\title{
Hardness and Thermal Analysis in Welded Butt Joint of Hybrid Aluminium (LM25) Metal Matrix Nano Composite Cylindrical Rod using TIG Welding Process
}

\author{
V. Deepakaravind ${ }^{1 \dagger}$, P. Gopal ${ }^{2}$ and A. Viswanathan ${ }^{3}$ \\ ${ }^{1}$ Department of Mechanical Engineering, Velammal Institute of Technology/ Chennai601204, Tamil Nadu, India \\ ${ }^{2}$ Department of Automobile Engineering/Anna University Trichy-620024, TamilNadu, India \\ ${ }^{3}$ Department of Physics/Anna UniversityTrichy-620024, TamilNadu, India
}

†Corresponding Author Email: deepakaravindv@gmail.com

(Received May 15, 2018; accepted July 18, 2018)

\begin{abstract}
An attempt is made in optimization of welding parameters of Hybrid LM25 Aluminium Metal Matrix Nano Composite (AMMNC) Cylindrical Rod made by using stir casting method. $2 \%$ of nano Silicon carbide (SiC) particles along with 3\% of nano alumina is added with Base metal LM25 Aluminium alloy for producing Hybrid AMMNC Samples. Joining of this Hybrid AMMNC samples are done by using TIG welding Process. By conducting experiment, effect of welding parameters such as welding pulse current, Arc Voltage and shielding gas flow rate on welded Hybrid AMMNC Samples are studied. To develop the regression equation and predict the weld centre micro hardness value on welded AMMNC Samples Design-Expert version 11 statistical software is used. From the predicted value of weld centre micro hardness value $100 \mathrm{HV}$ has been observed from the Empirical model results. Therefore to optimize welding pulsed current, Arc Voltage and Shielding gas flow rate parameters are resulted in higher micro hardness value as observed in welded Hybrid AMMNC Samples, which implies that strength of the weld is increased with respect to optimize welding parameters. In addition to investigate the temperature distribution in optimized Hardness value of welded AMMNC sample. Then heat fusion in the size and distribution of heat source, the travel speed, the heat conduction in the welding direction and the surface heat loss during welding are considered. A numerical scheme is developed to solve the three dimensional problem. With the help of a mathematical model, the effect of welding parameters such as heat input of the weld, preheating of the work piece and moving velocity of heat source on weld penetration in welded AMMNC cylindrical rod samples are discussed. The steadystate temperature profiles of the welded AMMNC samples are solved by finite difference method. In addition, a thermal experiment such as Heat Flux Differential Scanning Calorimeter Experiment is conducted to verify the theoretical results and Numerical results in ANSYS software. The predicted values from the proposed model are compared with the experimental data of optimized welded AMMNC samples.
\end{abstract}

Keywords: LM25 Al Metal Matrix Nano Composite Cylindrical Rod (AMMNC); Tungsten Inert Gas Welding (TIG); Silicon Carbide (SiC); Nano Particle (np).

\section{INTRODUCTION}

Nanoscience and technology is a broad area of research and development activity that it has been growing worldwide in the past decades by El-Sabbagh (2015). Nano crystalline materials are single phase or multiphase polycrystals, where the crystal size is in the order of few nanometers about 40 to $80 \%$ of the atoms are in the grain boundaries by by El-Sabbagh (2016). The matrix phases are separated the magnetic particles and changes in the magnetic exchange interaction. In this paper main functionally graded material and the pure alloy is processed by using the Stir casting method. LM 25 alloy is reinforced with 2 wt \% of Beta Phase Nano Silicon Carbide with $45 \mathrm{~nm}$ Scale Range and $3 w t \%$ of Beta phase of Nano Alumina Particle with $50 \mathrm{~nm}$ Scale range. These nano particles of Silicon Carbide and Alumina are reinforced LM25 Aluminium alloy with Liquid Processing Technique, i.e. Stir casting method and later to seek for possibilities of successful joining with TIG process, for possible structural applications. 
The present study deals with an experimental study carried out in order to optimize the process parameters Current (A), Shielding gas flow rate $(1 / \mathrm{m})$ and Arc Voltage (V). These performances are measured and evaluated are namely MicroHardness Value (HV) for TIG welding of $\mathrm{Al} 356 / 2 \% \mathrm{SiC}_{\mathrm{np}} / 3 \% \mathrm{Al}_{2} \mathrm{O}_{3 \text { np. }}$. The results are analyzed using One-Factor MultilevelCategorical Factor technique. The optimal values of micro-hardness are welding pulse current, arc voltage and shielding gas flow rates are $120 \mathrm{~A}$, $21 \mathrm{~V}$ and $12 \mathrm{l} / \mathrm{m}$ respectively.

The heat flux DSC belongs to the class of heatexchanging calorimeters by Shorowordi (2003). In the heat flux DSC, the sample and the reference are heated from the same source and the temperature difference is measured. This signal is converted to a power difference using the calibration sensitivity by Wang (2009). The characteristic feature of this measuring system is that the main heat flow from the furnace to the sample and reference containers passes symmetrically through a thermally conductive disk. The sample containers are positioned on this disk symmetrical to the center, and the temperature sensors are integrated. Each temperature sensor covers more or less the area of support of the respective container (crucible, pan) so that calibration can be carried out independent of the sample position inside the container. To minimize measurement uncertainties, the arrangement of the containers and the temperature sensors must always be the same by Razal (2012) and Karunakaran (2011).

\section{EXPERIMENTATION}

\subsection{Fabrication of Aluminium Metal Matrix Nano Composite Samples (AMMNC)}

From the Volume fraction table to take the reinforcement fraction of Nano $\mathrm{SiC}$ and Nano Alumina in to the base matrix of LM25 Al. The experimental arrangements consist of the main furnace and components along with four mild steel stirrer blades. This metal-matrix of $95 \%$ weight $\mathrm{Al}, 2 \% \mathrm{wt}$ of $\mathrm{SiC}$ Nano Particles and $3 \% \mathrm{wt}$ of A12O3np is kept into the furnace at the same temperature. The temperature rate of the furnace should be controlled at $7500 \mathrm{C}$ in final mixing process. The degassers are removed all the trapped gases from the mixture in the crucible and ensured that the temperature of the mixture in the crucible could not get transferred easily to the atmosphere. The furnace completely melts the pieces of aluminium alloy and the powders of nano alumina and nano silicon carbide. The stirring mechanism have applied at lowered into the crucible inside the furnace and set at the required depth of the material. The automatic stirring of the material takes place for $10 \mathrm{~min}$ with $750 \mathrm{rpm}$ of stirring rate, thereby uniformly dispersing of the additive reinforcement of nano particles Silicon Carbide and Alumina in to the aluminium alloy matrix of LM25 Al alloy.
Table 1 Volume fraction of AMMNC (LM25Al MMNC)

\begin{tabular}{|c|c|c|c|}
\hline Sample & LM25 Al & Nano SiC & $\begin{array}{c}\text { Nano } \\
\text { Alumina }\end{array}$ \\
\hline Sample 0 & $95 \%$ & $2 \%$ & $3 \%$ \\
\hline
\end{tabular}

The preparation of the AMMNC sample by pouring of Casting billet size of $20 \mathrm{~mm}$ diameter and 300 $\mathrm{mm}$ Length showed in the figure1.In Figure 2 is clearly shows the AMMNC Sample 0 with dimension of $20 \mathrm{~mm}$ diameter and Length $300 \mathrm{~mm}$.

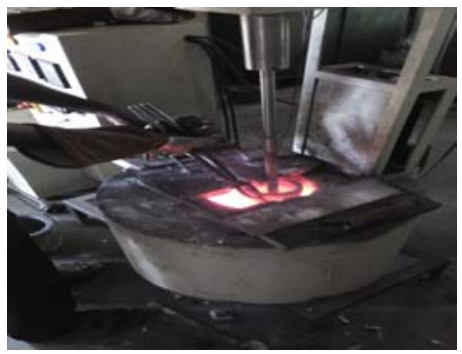

Fig. 1. Stirring of molten metal in the furnace

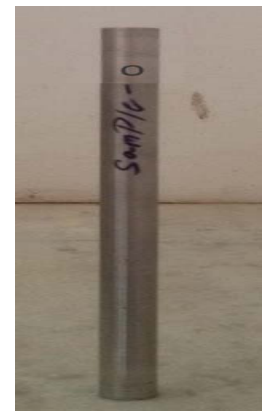

Fig. 2. AMMNC SAMPLE

\subsection{Welding of AMMNC Samples by using TIG welding Process}

In this current study, tungsten filler wires diameter $0.8 \mathrm{~mm}$ is used as the welding materials. In the experiments, Francis Magic Wave 3000 type welding machine is used. In this type of machine heat generated by the electric arc is used to melt and joint the base metal. Gas shielding for welding is kept in the flowing rate of $10,12 \& 14 \mathrm{lit} / \mathrm{min}$. Current intensity and welding speed are chosen as $80 \mathrm{~A}$ and $3.5 \mathrm{~mm} / \mathrm{sec}$., respectively. Pulse Frequency is $2 \mathrm{~Hz}$. During this welding, welding gun is controlled manually and the welding wire has fed manually into the welding area. After welding, specimens are cooled in the air. In this way the AMMNC cylindrical samples are joining the butt welding by using TIG welding process. On the basis of developing experiment matrix as shows in the table 2 .

Table 2 Working range of the TIG welding

\begin{tabular}{|c|c|c|c|c|c|}
\hline \multirow{2}{*}{ Sno } & Parameter & Unit & \multicolumn{3}{|c|}{ Levels } \\
\cline { 4 - 6 } & & -1 & 0 & 1 \\
\hline 1 & Voltage & $\mathrm{V}$ & 16.5 & 19.5 & 21.1 \\
\hline 2 & Current & $\mathrm{A}$ & 100 & 120 & 140 \\
\hline 3 & $\begin{array}{c}\text { Shielding } \\
\text { Gas Flow } \\
\text { rate }\end{array}$ & $1 / \mathrm{m}$ & 10 & 12 & 14 \\
\hline
\end{tabular}


From the master sample AMMNC Cylindrical rod $20 \mathrm{~mm}$ diameter and Length $300 \mathrm{~mm}$ and cut the 20 $\mathrm{mm}$ diameter with Length $15 \mathrm{~mm}$, then these samples are divided in to two halves of $10 \mathrm{~mm}$ diameter with $15 \mathrm{~mm}$ of two piece samples. Afterwards joining the butt joint of two halves of AMMNC Samples which as show in the below figure 3 .

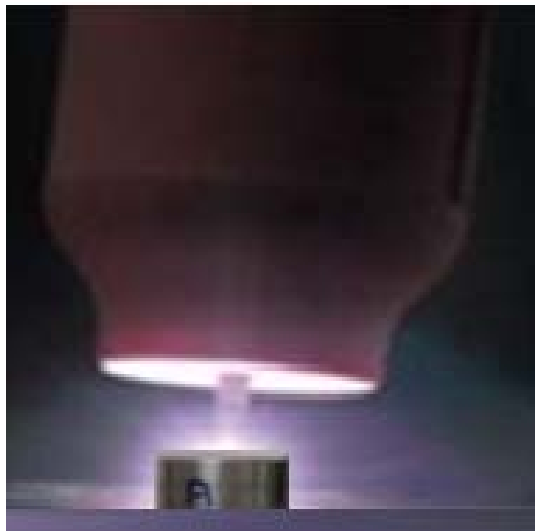

Fig. 3. TIG Welding of AMMNC Samples 1 to 20

Experimental runs are decided using 1 factor and 3 levels as show in the above table 2 . Then process parameters have taken as Voltage $(16.5 \mathrm{~V}, 19.5 \mathrm{~V}$ and $21.1 \mathrm{~V})$, Current (100A, 120A and 140A) and Shielding gas flow rate as $10 \mathrm{l} / \mathrm{m}, 12 \mathrm{l} / \mathrm{m}$ and $14 \mathrm{l} / \mathrm{m}$ ) for join the two halves of AMMNC samples $20 \mathrm{~mm}$ diameter with $15 \mathrm{~mm}$ long samples are joining the butt joint of AMMNC cylindrical samples. In the similar way from the master sample 0 to cut the AMMNC cylindrical rod sample as $20 \mathrm{~mm}$ diameter with $15 \mathrm{~mm}$ length of 20 samples. Then Samples 1to 20 for various weld trial run by using TIG welding process, which as shown in the below Figure 4. After the joining of weld trial run of Samples 1 to 20 to conduct the Micro hardness test in the various weld trial run of welded AMMNC Samples1 to 20 which as show in the below Figure 4.

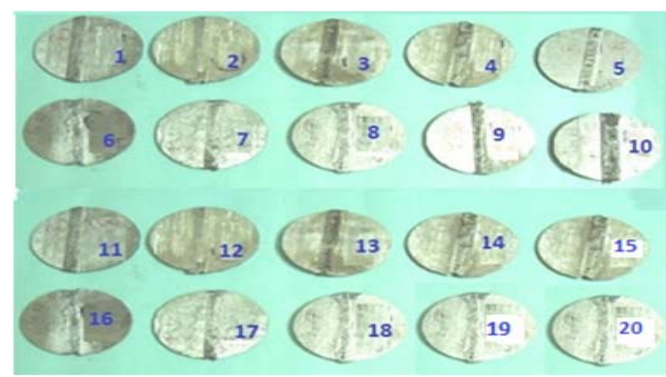

Fig. 4. Welded AMMNC Samples 1to 20

\subsection{Micro Hardness Test}

Micro hardness observed on weld centre $1 \mathrm{~mm}$ below the welded surface is measured using Shimadzu Vickers micro hardness tester as show in the below figure 5. In this hardness test measured the resistance of a solid to permanent shape change. When a force $25 \mathrm{~g}, 50 \mathrm{~g}, 100 \mathrm{~g}, 200 \mathrm{~g} \& 500 \mathrm{~g}$ are applied to the Welded specimen of AMMNC
Samples 1 to 20. The hardness test measures the resistance of a solid to Permanent shape change. It is carried out in this work to find out the deformation of the welded AMMNC samples under constant load applied in the specimen as show in the figure 5 and measuring the actual Micro hardness value as in the below table 4 .

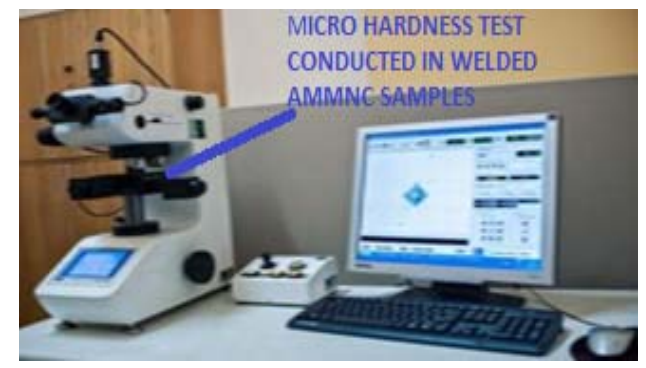

Fig. 5. Micro Hardness Test conducted in Welded AMMNC Samples 1to 20

\section{DEVELOPING EMPIRICAL MODEL}

Both Statistical and mathematical techniques can be used for developing empirical relationships. In these techniques the influence of parameters on response can be studied easily. It is used for optimizing the conditions based on desired response and also be employed for predicting the response experimental design was done in Design Expert Version 11 statistical software package making using of Multi level category array. Regression equation and correlation coefficients are also developed using Design Expert 11 statistical software. Peak current, Arc voltage and Shielding gas flow rate are the functions of weld centre micro hardness. The empirical model developed using regression equation includes main factors and first order interaction of all factors. This can be expressed in the form of Fourth order polynomial equation as specified in equation (1).

\subsection{Final Equation in Terms of Coded Factors}

Micro Hardness Value of Heat Affect Zone in Welded AMMNC samples

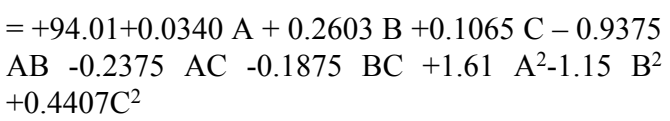

Micro Hardness Value of Welding Zone in Welded AMMNC samples

$=+93.63-0.9386 \mathrm{~A}-2.56 \mathrm{~B}+0.603 \mathrm{C}-0.400 \mathrm{AB}-$

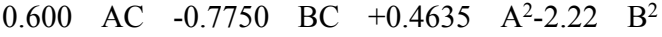
$+0.1807 \mathrm{C}^{2}$

The equation in terms of coded factors can be used to make predictions about the response for given levels of each factor. By default, the high levels of the factors are coded as +1 and the low levels are coded as -1 . The coded equation is useful for identifying the relative impact of the factors by comparing the factor coefficients 
Table 3 Regression Equation of Micro Hardness Value of WZ and HAZ in Welded AMMNC Samples 1 to 20

\begin{tabular}{|c|c|c|}
\hline Response & Regression Equation & $\begin{array}{c}\text { Coefficient of } \\
\text { correlation } \\
\left(\mathrm{r}^{2}\right)\end{array}$ \\
\hline $\begin{array}{l}\text { Micro Hardness Value } \\
\text { of WZ in welded } \\
\text { Nano Composite }=\end{array}$ & $\begin{array}{c}\text { 611.94+0.103 Welding Current }+16.10 \text { Shielding Gas } \\
\text { Flow Rate }+34.742 \text { Arc Voltage-0.0160 Welding } \\
\text { Current * Shielding Gas Flow Rate- } 0.240 \text { Welding } \\
\text { Current * Arc Voltage-0.310 Shielding Gas Flow } \\
\text { Rate * Arc Voltage }+0.018541 \text { Welding Current }{ }^{2}- \\
0.0889 \text { Shielding Gas Flow Rate }{ }^{2}+0.7227 \text { Arc }^{-} \\
\text {Voltage }^{2} \text {-- (3) }\end{array}$ & 0.95 \\
\hline $\begin{array}{l}\text { Micro Hardness Value } \\
\text { of HAZ in welded } \\
\text { Nano Composite }=\end{array}$ & $\begin{array}{c}\text {-272.53-2.354 Welding Current+9.7491 Shielding } \\
\text { Gas Flow Rate }+2.049 \text { Arc Voltage }+0.0037 \text { Welding } \\
\text { Current * Shielding Gas Flow Rate+0.005435 } \\
\text { Welding Current* Arc Voltage-0.075000 Shielding } \\
\text { Gas Flow Rate * Arc Voltage }+0.064296 \text { Welding } \\
\text { Current }{ }^{2}-0.046012 \text { Shielding Gas Flow } \\
\text { Rate }^{2}+1.76274 \text { Arc Voltage }{ }^{2}--(4)\end{array}$ & 0.95 \\
\hline
\end{tabular}

Table 4 Micro Hardness Value Trial run of Welded AMMNC Samples

\begin{tabular}{|c|c|c|c|c|c|c|}
\hline $\begin{array}{c}\text { Run } \\
\text { Order }\end{array}$ & $\begin{array}{c}\text { Actual } \\
\text { Value of } \\
\text { HAZ in } \\
\text { welded } \\
\text { AMMNC }\end{array}$ & $\begin{array}{c}\text { Predicted } \\
\text { Value of } \\
\text { HAZ in } \\
\text { welded } \\
\text { AMMNC }\end{array}$ & $\begin{array}{c}\text { Percentage } \\
\text { Error of HAZ } \\
\text { in Welded } \\
\text { AMMNC (\%) }\end{array}$ & $\begin{array}{c}\text { Predicted } \\
\text { Value of WZ } \\
\text { in welded } \\
\text { AMMNC }\end{array}$ & $\begin{array}{c}\text { Predicted } \\
\text { Value of WZ } \\
\text { in welded } \\
\text { AMMNC }\end{array}$ & $\begin{array}{c}\text { Percentage } \\
\text { Error of WZ in } \\
\text { Welded } \\
\text { AMMNC (\%) }\end{array}$ \\
\hline 1 & 95 & 95.59 & -0.59 & 94 & 93.45 & 0.55 \\
\hline 2 & 96.5 & 98.67 & -2.17 & 92.5 & 91.53 & 0.97 \\
\hline 3 & 97.2 & 96.45 & 0.75 & 94 & 93.9 & 0.1 \\
\hline 4 & 99 & 96.45 & 2.55 & 93 & 93.9 & -0.9 \\
\hline 5 & 94.5 & 97.02 & -2.52 & 89.5 & 89.19 & 0.31 \\
\hline 6 & 96.5 & 96.45 & 0.05 & 93.5 & 93.9 & -0.4 \\
\hline 7 & 95.5 & 98.36 & -2.86 & 90.5 & 90.67 & -0.17 \\
\hline 8 & 96 & 96.39 & -0.39 & 86.5 & 87.65 & -1.15 \\
\hline 9 & 97 & 96.45 & 0.55 & 94.7 & 95.13 & -0.43 \\
\hline 10 & 100 & 98.12 & 1.88 & 97.5 & 93.9 & 3.6 \\
\hline 11 & 98.2 & 96.65 & 1.55 & 96.5 & 97.4 & -0.9 \\
\hline 12 & 99.2 & 98 & 1.2 & 92 & 93.57 & -1.57 \\
\hline 13 & 95.6 & 96.17 & -0.57 & 94.5 & 93.1 & 1.4 \\
\hline 14 & 98 & 96.05 & 1.95 & 95.7 & 96.26 & -0.56 \\
\hline 15 & 90 & 91.57 & -1.57 & 96.7 & 93.37 & 3.33 \\
\hline 16 & 95 & 92.63 & 2.37 & 93.1 & 92.86 & 0.24 \\
\hline 17 & 92 & 92.99 & -0.99 & 95.5 & 94.89 & 0.61 \\
\hline 18 & 93 & 88.75 & 4.25 & 92.5 & 91.39 & 1.11 \\
\hline 19 & 89 & 91.57 & -2.57 & 87.5 & 93.37 & -5.87 \\
\hline 20 & 84.50 & 87.37 & -2.87 & 82.5 & 82.77 & -0.27 \\
\hline
\end{tabular}

\subsection{Final Equation in Terms of Actual} Factors

The regression coefficients depend on, the main factors and interaction of factors. Regression coefficient are solved in Design Expert 11 statistical software, to obtain regression equations and predict the weld centre micro hardness.

Correlation Coefficient ' $r$ ', shows how nearer the predicted values to the experimental values. 
Correlation coefficients for regression equations are shown in below Table3.

The regression coefficients depend on, the main factors and interaction of factors. Regression coefficient are solved in Design Expert 11 statistical software, to obtain regression equations and predict the weld centre micro hardness. Correlation Coefficient ' $r$ ' ' shows how nearer the predicted values to the experimental values. Correlation coefficients for regression equations are shown in Table 3. Values of correlation are having higher values and it is showing significant effect of main factors and their interactions with response. This has been checked by using Analysis of Variance (ANOVA). Regression equations are shown in the table 3.

\section{THERMAL ANALYSIS OF WELDED JOINT AMMNC CYLINDRICAL ROD SAMPLE}

\subsection{Heat Flux DSC - Single Furnace}

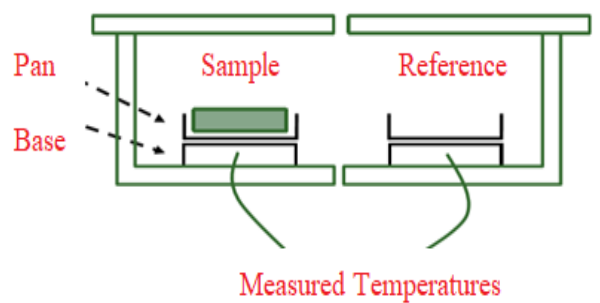

Fig. 6. Heat Flux DSC in Welded Trial run of AMMNC Sample10 is placed in Single furnace

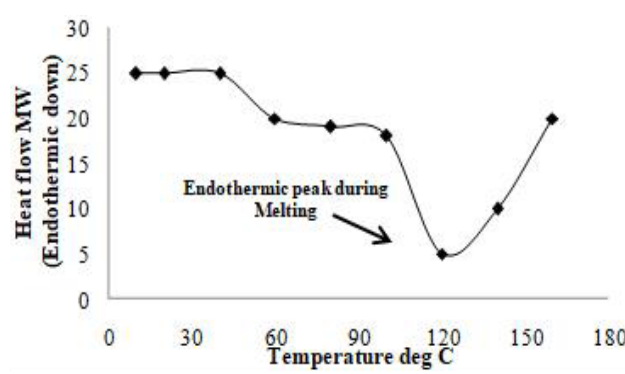

Fig. 7. Trend analysis of Heat Flow in Optimize trial run of welded AMMNC samples

In the above figure 6 Heat flux Differential Scanning Calorimeter (DSC) .where the optimized trial run of welded AMMNC sample 10 is placed in the pan and the furnace are controlled to program temperature profile. It is measured with the temperature difference between sample of welded AMMNC sample 10 and reference aluminium sample. Afterwards it is calculated along with the corresponding heat flow in to or out of welded AMMNC sample from measuring data. The furnaces are controlled to programmed temperature profile of welded AMMNC sample 10. Finally by measuring the difference in energy input and output are required to achieve temperature .Moreover Faster heating and cooling rates are observed in the below figure 7 .It has clearly shows better resolution and sensitivity are observed in the Heat flow rate at $5 \mathrm{MW}$ and Temperature $125^{\circ} \mathrm{C}$ Endothermic Peak during melting in the welded AMMNC samples 10.

\section{RESULTS AND DISCUSSION}

\subsection{Analysis of Contour Plots}

Contour plots are generated by using Design Expert software version 11 to study the interaction effect of pulsed current TIG welding parameters such as pulse on welding current, Shielding gas Flow rate and Arc voltage on weld center micro hardness. Figure 6 to Figure 11 shows contour plots which predict the weld center micro hardness with $\mathrm{X}$-axis as base current \& $\mathrm{Y}$-axis as Welding Current. Shielding Gas Flow rate $(1 / \mathrm{m})$ and pulse frequency values were made constant in all graphs. Comparison of these graphs shows the effect of pulsed current parameters on weld center micro hardness. This is explained in the following sections. From the Figure 6 shows the Predicted Micro Hardness Value of Heat Affected zone in Welded AMMNC with respect to the Actual Micro Hardness Value. Whereas Lowest Micro Hardness value $84.5 \mathrm{HV}$ observed in the Trial Run order of $20^{\text {th }}$ Sample Welded AMMNC and Highest Micro hardness value $100 \mathrm{HV}$ shows in the Welding Trial Run order of $10^{\text {th }}$ Sample of Welded AMMNC as show in the Figure 8 as well as show in the above table 3 .

From the Figure9 shows the Predicted Micro Hardness Value of weld zone in Welded AMMNC with respect to the Actual Micro Hardness Value. Whereas Lowest Micro Hardness value 82.5 HV observed in the Trial Run order of $20^{\text {th }}$ Sample Welded AMMNC and Highest Micro hardness value 97.5 HV shows in the Welding Trial Run order of $10^{\text {th }}$ Sample of Welded AMMNC as show in the Figure 7 as well as show in the table 3. Optimized Micro hardness values for HAZ $100 \mathrm{HV}$ and WZ $97.5 \mathrm{HV}$ in pulse on welding time, arc voltage and shielding gas flow rates are $120 \mathrm{~A}$, 21 Vand $12 \mathrm{l} / \mathrm{m}$ respectively.

From the Figure 10 and Figure 11, Contour plotting shows Optimised Micro hardness value Heat Affected Zone is observed in Welding Trial Run Order of $10^{\text {th }}$ sample is $100 \mathrm{HV}$ as well as Micro hardness value weld zone is $97.5 \mathrm{HV}$. From the Figure 8 and 9 clearly shows that decrease in the difference in Pulse on Welding Current leads to decrease Micro hardness value in $\mathrm{HAZ}$ and $\mathrm{WZ}$ of welded AMMNC samples. Lowering Pulse on welding current leads to decrease Micro Hardness value of HAZ and WZ in welded AMMNC samples. Using regression equation, weld centre Micro Hardness is optimized. Here TIG welding parameters such as Pulse on welding current, shielding gas flow rate and arc voltage are developed for HAZ and WZ in above table 2. Increase in Pulse on welding current, shielding gas flow rate and arc voltage leads to Increase in higher weld of Micro hardness value observed in the above Table3. 
V. Deepakaravind et al. /JAFM, Vol. 11, Special Issue, pp. 79-89, 2018.

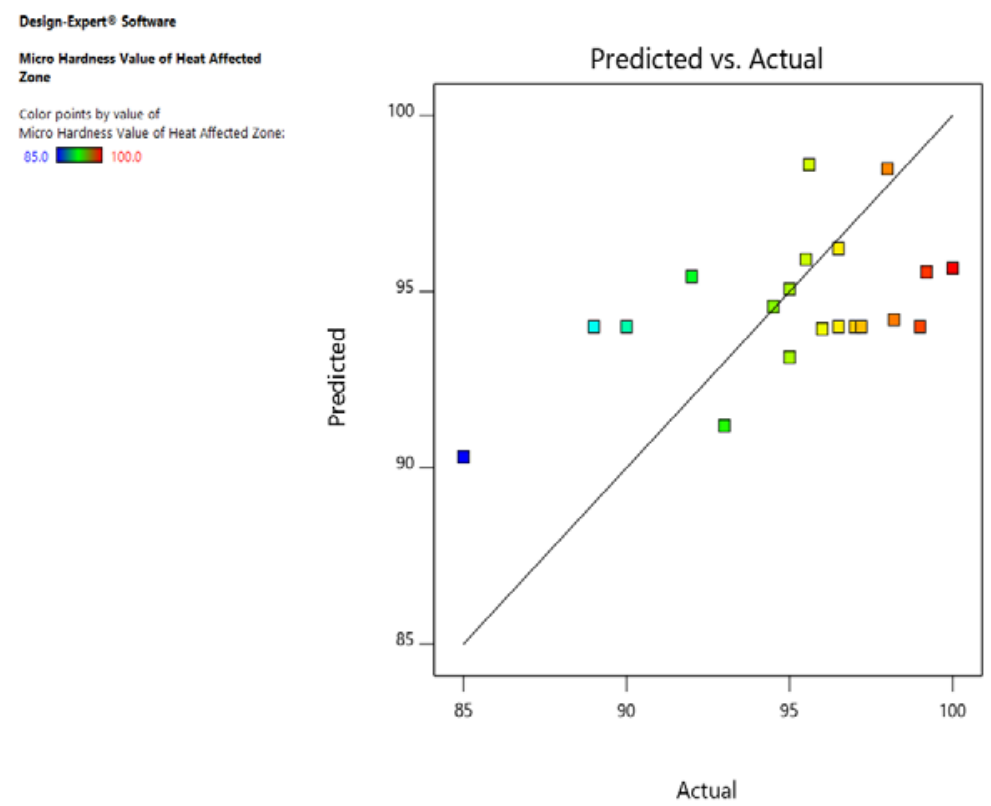

Fig. 8. Predicted Value of HAZ welded AMMNC Vs Actual Value of HAZ welded AMMNC

Design-Expert ${ }^{\circledR}$ Software

Micro Hardness Value of Welding Zone

Color points by value of

Micro Hardness Value of Welding Zone:

$82.5 \square 97.5$

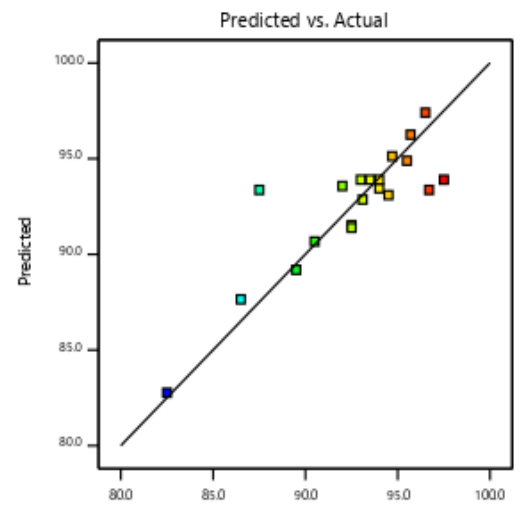

Actua

Fig. 9. Predicted Value of Weld Zone (WZ) vs Actual Value of Weld Zone (WZ) in Welded AMMNC Samples
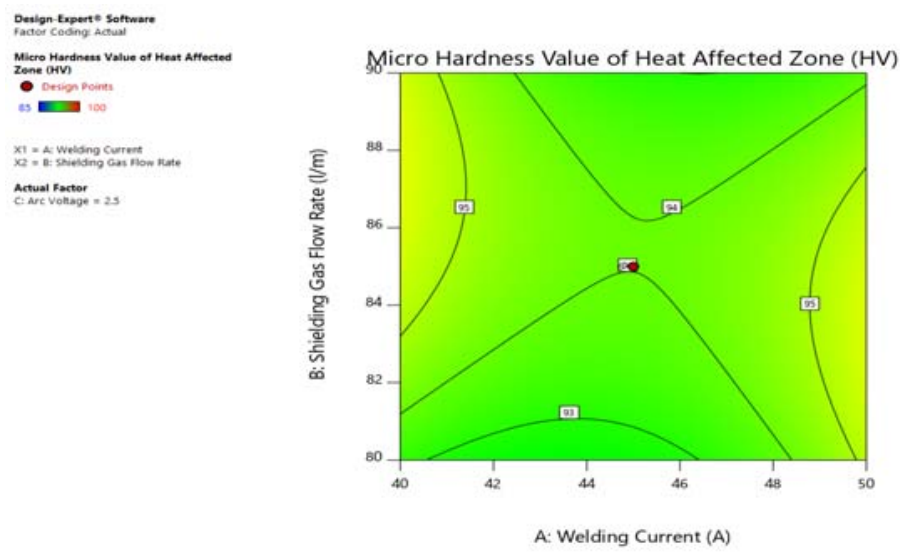

Fig. 10. Contour Plotting of Micro hardness value of Heat Affect Zone in welded AMMNC 

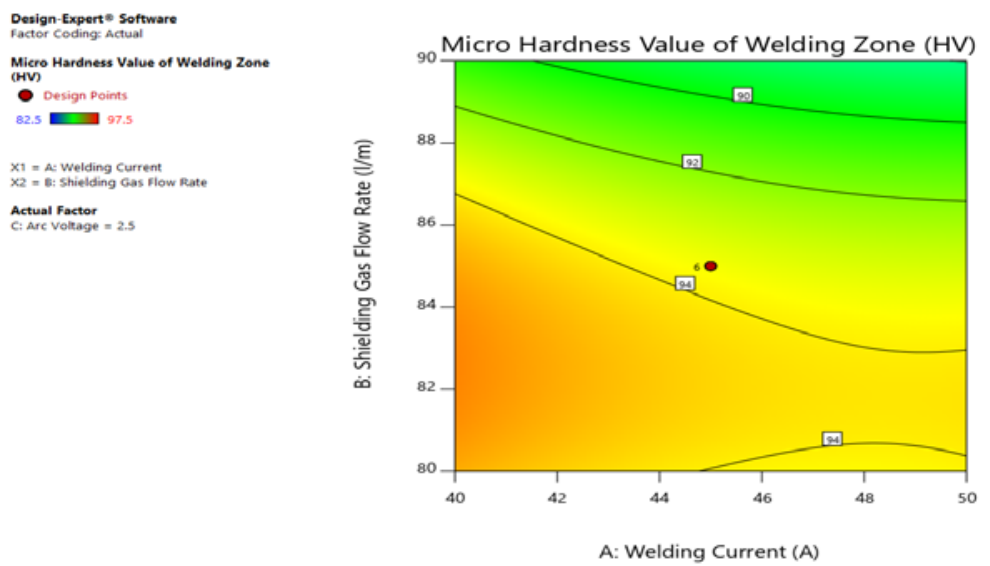

Fig. 11. Contour Plotting of Micro hardness value of Weld Zone in welded AMMNC

\subsection{Response surface Method for Optimization}

The first step is obtaining the optimum response settings, their after identified the important factors is to explore the region around the current operating trend conditions to decide whether directions are moved towards the optimum region. Generally, a first order regression model is maintained the effects and no interaction terms) sufficient at the current operating conditions for the operating conditions are usually far away from the optimum response settings. The experimenter is needed to be moving from the current operating conditions to the optimum region in the most efficient way of using the minimum number of experiments. This is done using the method of steepest ascent. In this method, the contour plot of the first order model is used to decide the settings for the next experiment, in order to move towards the optimum conditions. Consider a process where the response has been found to be a function of Multilevel-Categorical Factor technique. From the Regression equation 3 and 4 as formed the regression coefficient Micro hardness value of HAZ and WZ in welded AMMNC samples 1 to 20 . Now to really get a feel for how the response varies as a function of the chosen for display, select 3D surface from the Graph Toolbar, Then 3 dimensional display of the response surface. From the Factors tools to move the slide bar from A: Welding Current, Shielding gas flow rate $(1 / \mathrm{m})$ and C: Arc Voltage to the right. This presents a very compelling picture of how the response can be maximized as show in the below figure 12and 13
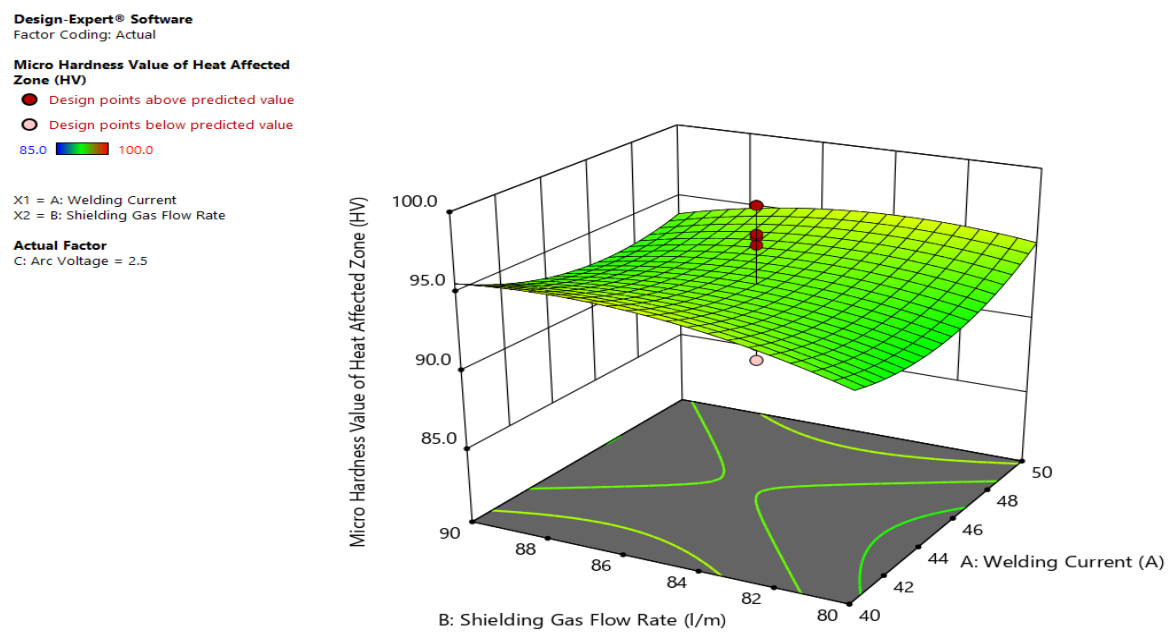

Fig. 12. RSM of Micro hardness value in Heat Affected Zone of welded AMMNC Samples 1 to 20

From the Figure 12 shows the Response Surface model for optimization of HAZ in welded AMMNC Samples 1to 20. From the above RSM plotted for Response Micro Hardness value of HAZ plotted with respect to the regression equation formation as show in the above table 2. Here green colour surface response curve denoted as optimize Micro Hardness value of HAZ in AMMNC as Welding Current 120A, Shielding Gas Flow rate $(121 / \mathrm{m})$ and Arc voltage $(21.1 \mathrm{~V})$. Whereas thick red circle is indicated as above the design point of the predicted value. In the Same way light red circle plotted 
indicated as Design point below the predict value. In this RSM graph Low Micro Hardness value HAZ is $85 \mathrm{HV}$ observed in the welding trial order of $20^{\text {th }}$ Sample and High Micro Hardness Value is 100 HV observed in the welding trial order of $10^{\text {th }}$ Sample.

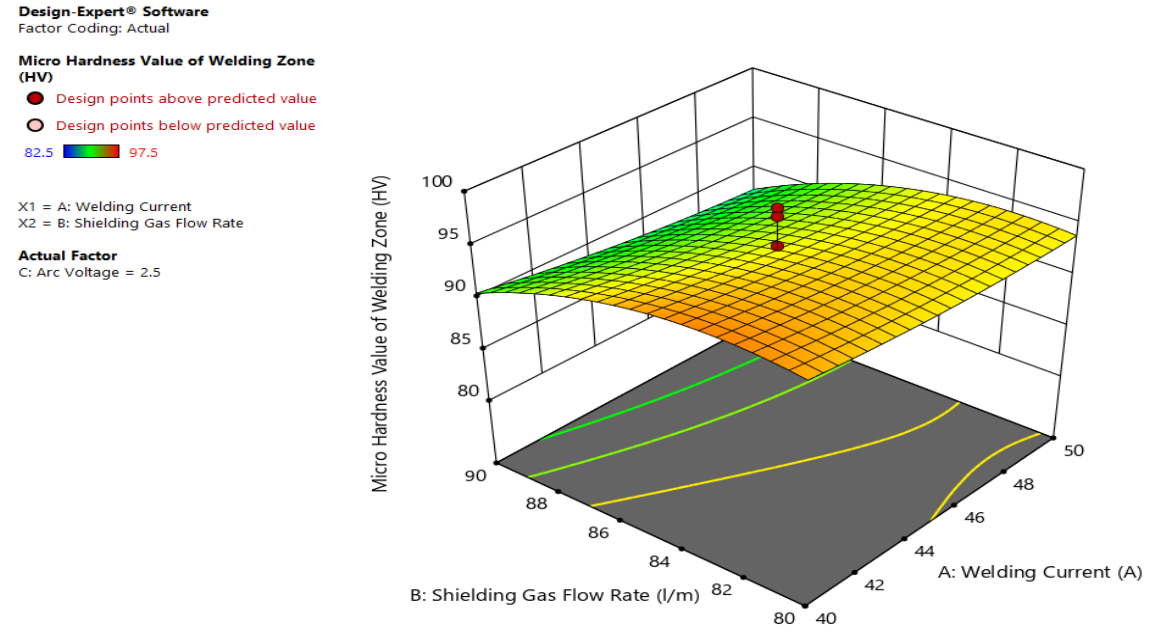

Fig. 13. RSM of Micro hardness value in Welding Zone of welded AMMNC Samples 1 to 20

From the Figure 13 shows the Response Surface model for optimization of $\mathrm{WZ}$ in welded AMMNC Samples 1to 20. From the above RSM plotted for Response Micro Hardness value of WZ with respect to the regression equation formation as show in the above table 2. Here green colour surface response curve denoted as optimize Micro Hardness value of WZ in AMMNC as Welding Current 120A, Shielding Gas Flow rate $(121 / \mathrm{m})$ and Arc voltage (21.1V). Other part of Response curve yellow in colour, which denoted as Lower Micro Hardness value of $82.5 \mathrm{HV}$. Whereas thick red circle is indicated as above the design point of the predicted value. In the Same way light red circle plotted indicated as Design point below the predict value. In this RSM graph Low Micro Hardness value HAZ is $82.5 \mathrm{HV}$ observed in the welding trial order of $20^{\text {th }}$ Sample and High Micro Hardness Value is $97.5 \mathrm{HV}$ observed in the welding trial order of $10^{\text {th }}$ Sample.

\subsection{Micro Structural Analysis by Using SEM Analysis}

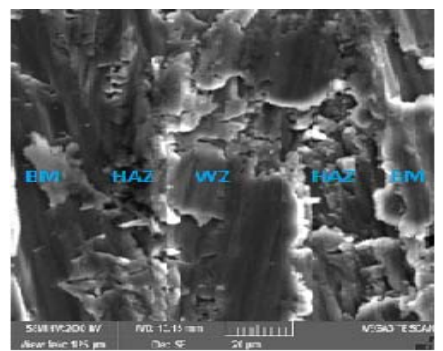

Fig. 14. Micro structural Analysis of Optimised weld Trial run of Sample 10 at Scale Range of $10 \mu \mathrm{m}$

The main principle of SEM is the bombarding of electrons and the secondary electrons which are reflected are formed and displayed in the Computer Screen. The sample holder stub is cleaned with acetone and dried in the sputter coater machine with
240 volts. After the cut the small rectangle pieces from the weld trial run order of sample 10. Then this sample microstructure is analyzed using SEM analysis. Many micro cracks and porous sites are observed in the sample which is attributed of joining the butt joint of welded AMMNC samples and many cracks and Porosity occurs in the Heat Affected zone due to Arc glares, Arc spatters and Overheating of tungsten electrode. Whereas less cracks are available in the Welding Zone (WZ) as well Base Metal Zone (BM) in Welded AMMNC trial run order of Sample 10 as show in the above figure 14 .

\subsection{Thermal Analysis Experimentation Results}

The objective of this experiment is to verify the numerical solutions in finite cylindrical rods of equation the equation is

$\alpha\left(\partial^{2} \mathrm{~T} / \partial \mathrm{x}^{2}+\partial^{2} \mathrm{~T} / \partial \mathrm{y}^{2}+\partial^{2} \mathrm{~T} \partial \mathrm{z}^{2}\right)+\mathrm{U} \partial \mathrm{T} / \partial \mathrm{x}=0$

In the experiment, AMMNC cylindrical rod samples are used as the work pieces to be welded with gas tungsten arc welding machine under various welding conditions as show in the above table 2. In addition to the experimental conditions and thermal properties of the welded cylindrical rod AMMNC samples are the same as those used in the numerical calculation as show in the below Table 5 . The physical properties are used in the calculations of fixed values at $300^{\circ} \mathrm{C}$, which is approximately the average value of room temperature and melting temperature are measured by using thermocouple. Here the effective liquid conductivity is 1.5 times higher than the value of the solid thermal conductivity whereas the specific heat of welded aluminium metal matrix is equivalent to solid one. GTA welding parameters are welding voltage $21 \mathrm{~V}$, welding current, $120 \mathrm{~A}$, travel speed: $3 \mathrm{~mm} / \mathrm{sec}$, respectively. Oxide films are polished off the surfaces of the sample before conducting the 
experiment. The polished surfaces are cleansed with acetone. Furthermore, the work pieces of the optimised samples are thermally insulated from the fixtures in order to avoid heat sinks during welding. Argon gas is used for both welding and protecting the underside of the cylindrical rod welded AMMNC samples. Twelve K-type thermocouples are positioned in the work pieces as shown in below Figure 15(a) \&15(b), six on the top and six on the bottom surfaces of the welded AMMNC cylindrical rod samples. All the thermocouples are pre calibrated by a quartz thermometer with $0.5^{\circ} \mathrm{C}$ precision and all of the data signals are collected and converted by a data-acquisition system (a hybrid recorder). Data-acquisition systems are transmitted the converted signals through a general purpose interface bus to the host computer for further operation system. The experiments are repeated under varying process variables such as arc current, travel speed and initial temperature of the welded cylindrical rod AMMNC samples. Detailed experimental procedures are studied from the previous investigation [8].

In the present work, using ANSYS, numerical simulations of welding of AMMNC components are carried out. Experimentation is done in the established automatic TIG welding machine setup and interfacial temperature is measured on-line using infrared detector during the welding process. The temperature profile generated by Data Temp MX software during experimentation is shown in Figure 16. Experimental results obtained are used to validate the numerical results as show in the below figure 17.

Using FEA technique, thermal effects of the TIG welding process are simulated and the predicted temperature values are compared with the experimental values. Figure 17 shows that the trend of the time temperature plots are predicted by finite element heat flow model has a similar tendency with the experimental measurements. The heating curve is predicted by the numerical model has a closer degree of agreement with the experimental temperature profile. But the cooling curve predicted by the numerical model has a maximum of $13.7 \%$ error deviation from the experimental values. The Finite Element model is based on the assumption that the heat generated at the interface is transferred to the base materials Flash formation and relative movement of two components are not considered in the model. Hence, the graph plotted by numerical results has a shift towards the right of the experimental results as show in the above figure 17.

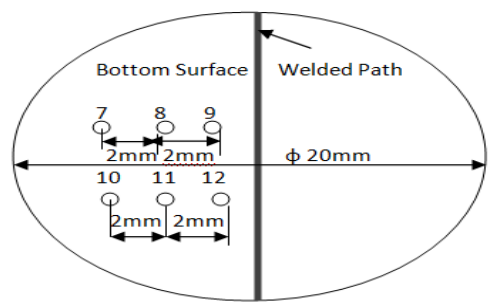

Fig. 15(a)

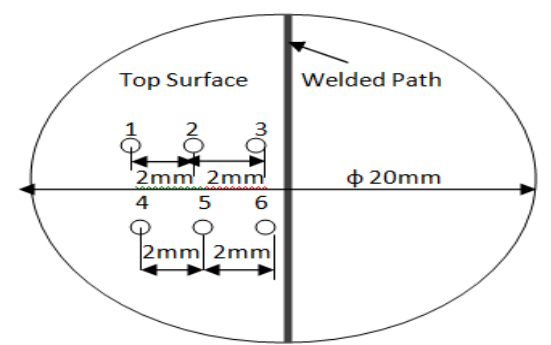

Fig. 15(b)

Fig. 15(a) \& (b). Locations of the welded path and thermocouples on the top and bottom surfaces of the welded AMMNC Sample 10

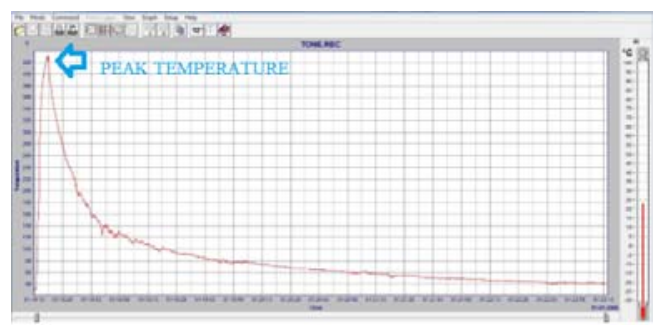

Fig. 16. Measured thermal profiles conducted in nearer to weld zone of welded AMMNC samples 10

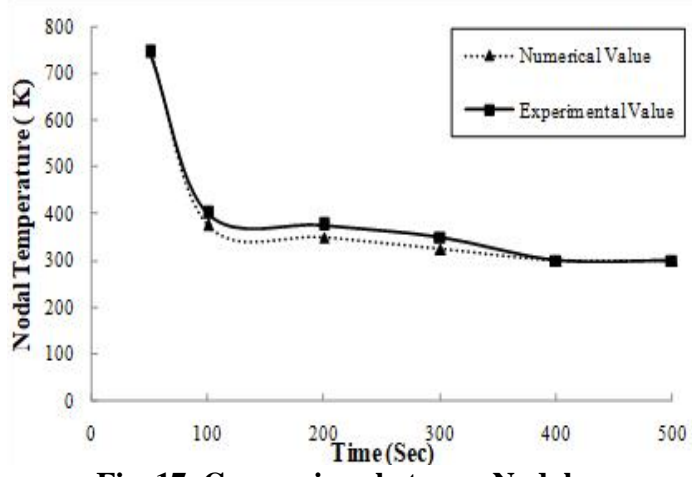

Fig. 17. Comparison between Nodal

experimental and numerical values at weld interface AMMNC samples 10

\subsection{Heat Flux Experimentation}

The temperature at the interface of welding sample of AMMNC sample and Heat affected zone are determined by the heat flux and the temperature reached by the material determines melting occurred in the welded AMMNC samples. Heat flux at every point signifies the level (strength) of weldment of AMMNC sample 10 as show in the above figure 10 . The recorded peak temperature value is $450^{\circ} \mathrm{C}$ at the interface of welding zone and $470^{\circ} \mathrm{C}$ at the heat affected zone. $65 \%$ of the melting point of base metal zone in welded AMMNC samples with the melting point of aluminium is $650^{\circ} \mathrm{C}$. Figure 18 shows the heat flux along the axial direction of the samples. Whereas in the above figure 18 show the hottest zone in red colour is with the heat flux $1.5 \times 10^{5} \mathrm{~W} / \mathrm{m}^{2}$ is found near the weld zone. In this region dynamically recrystallization takes place as revealed in the SEM images as show in the below figure 18C. 
4.6 Thermal Gradients of welded AMMNC Samples 10

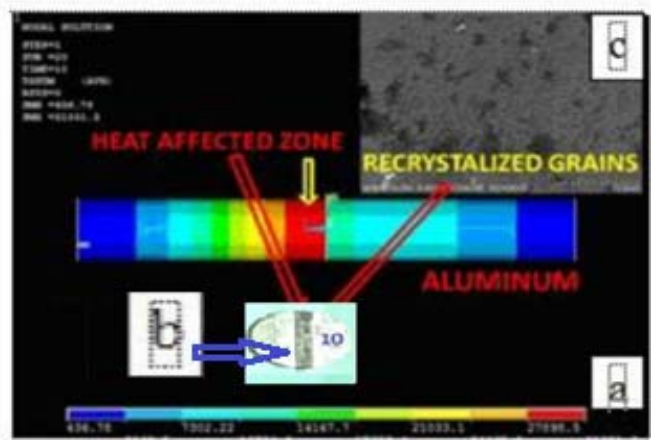

Fig. 18(a). Prediction of thermal gradient zone of Welded AMMNC Samples 10, Fig.18 (b). Welded showing marks of heat affected zone Figure 18(c) SEM micrograph showing recrystalized grains of welded AMMNC sample 10

Here the thermal diffusivity of welded AMMNC sample is $82.18 \times 10^{-6} \mathrm{~m}^{2} / \mathrm{s}$ as shown in the above Figure $18 \mathrm{a}$, the thermal gradient is high thermal diffusivity value as show in the welded interface. Due to this high thermal gradient as show in the area near the interfacial region is affected thermally as thick yellow colour show in the above Figure 18 b.Light yellow colour of heat affected zone visible near the weld interface. This mark of heat affected zone is clearly high thermal gradient near the weld interface of the numerical model. The grains in this region are recrystalized and it has lead to further reduction in grain size in the heat affected region as show in the Figure 18(c).

\section{CONCLUSION}

1. When peak welding current is greater than 120 $A$, it resulted in excessive penetration of the weld. Lack of fusion and incomplete penetration are resulted when peak current was less than $120 \mathrm{~A}$.

2. When the Shielding gas flow rate is less than $12 \mathrm{l} / \mathrm{m}$ weld trial run order of samples showed weld beads similar to that of constant current TIG welding. Arc glares and arc spatters are observed when arc voltage was greater than $19.5 \mathrm{~V}$

3. Overheating of tungsten electrode is observed when arc voltage is greater than $21.1 \mathrm{~V}$ and $140 \mathrm{~A}$, it resulted in poor weld bead surface appearance as show in the above Figure4.

4. Many micro cracks and porous sites are observed in the sample which is attributed of joining the butt joint of welded AMMNC samples and many cracks and Porosity occurs in the Heat Affected zone due to Arc glares, Arc spatters and Overheating of tungsten electrode.

5. Whereas less cracks are available in the Welding Zone (WZ) as well Base Metal Zone (BM) in Welded AMMNC trial run order of Sample 10 as show in the above figure 12 .
6. Heat Flux DSC experiment is used for measuring the difference in energy input and output are required to achieve temperature .Moreover Faster heating and cooling rates are observed in the below figure 7 .It has clearly shows better resolution and sensitivity are observed in the Heat flow rate at $5 \mathrm{MW}$ and Temperature $125^{\circ} \mathrm{C}$ Endothermic Peak during melting in the welded AMMNC samples 10.

7. A thermal effect during TIG welding of AMMNC is investigated through numerical simulations using finite element analysis. The following conclusions can be drawn from the study:

a. Numerical simulation of TIG welding of AMMNC samples using ANSYS has been carried out and the simulated results are compared with experimental results. The simulation results are in good agreement with the experimental values for TIG welding of AMMNC samples

b. Using the non-linear numerical model, nodal temperature and heat flux during the continuous TIG welding process are predicted as show in the Figure 18

c. A simple mathematical model has been developed based on finite element analysis of one dimensional heat flow in Modelling of AMMNC cylindrical rod samples. The results are compared with that of the numerical results generated by ANSYS as show in the above figure 18A fair agreement is found between the mathematical and numerical results.

d. Numerical investigation of heat flow in TIG welding process has been carried out with small time increments. Results show that the heat dissipation is high at aluminium in left side whereas the heat dissipation is less in the right side of welding of AMMNC sample. This is due to the change in material properties of the two similar metals. Since the thermal conductivity of aluminium is high the heat transfer is high in the left side of AMMNC samples.

e. The welded AMMNC sample joint shows yellow marks of heat affected zone near the weld interface side of AMMNC samples10.This further confirms the predicted numerical results by numerical model. Because of the low thermal diffusivity of welded AMMNC sample10, the heat flow is closer to the region near the weld interface and results in visible appearance of heat affected zone in the right hand side of welded AMMNC side.

\section{ACKNOWLEDGEMENTS}

I am acknowledging my guide, colleague and my college Principal, who are all helping me to complete the project.

\section{REFERENCES}

Ahmed, M., A. M. El-Sabbagh, M. Soliman, M. A. 
V. Deepakaravind et al. /JAFM, Vol. 11, Special Issue, pp. 79-89, 2018.

Taha, H. and Palkowski (2013). Effect of rolling and heat treatment on tensile behaviour of wrought $\mathrm{Al}-\mathrm{SiCp}$ Composite prepared by stir-casting. Journal of Materials Processing Technology 213(10), 1669-1681.

El-Sabbagh, A., M. Soliman, M. Taha, and H. Palkowski (2012). Hot rolling behaviour of stir-cast Al 6061 and Al 6082 alloys - SiC fine particulates reinforced composites. Journal of Materials Processing Technology 212(2), 497508.

Karunakaran, N. and V. Balasubramanian (2011). Effect of pulsed current on temperature distribution, weld bead profiles and characteristics of gas tungsten arc welded aluminum alloy joints. Transactions of Nonferrous Metals Society of China. 21(2), 278-286.

Razal Rose, A., K. Manisekar and V. Balasubramanian (2012). Predication and optimization of pulsed current tungsten inert gas welding parameter to attain maximum tensile strength in AZ61A magnesium alloy. Materials and Design 37 (1), 334-348.

Shorowordi, K. M., T. Laoui,A. Haseeb, J. P. Celis, and L. Froyen (2003). Microstructure and interface characteristics of $\mathrm{B} 4 \mathrm{C}, \mathrm{SiC}$ and Al2O3 reinforced Al matrix composites - A comparative study. Journal of Materials Processing Technology 142(3), 738-743

Sozhamannan, G. G., S. Balasivanandha Prabu, V. S. K. Venkatagalapathy (2012).Effect of Processing Parameters on Metal Matrix Composites: Stir Casting Process. Journal of Surface Engineered Materials and Advanced Technology 2(1), 11-15.

Wang, X. H., O. T. Niu, O. T., Guan, S. K., Wang, L. J. and Cheng, D. F. (2009). Investigation on TIG welding of SiCp-reinforced aluminummatrix composite using mixed shielding gas and $\mathrm{Al}-\mathrm{Si}$ filler. Materials Science and Engineering: A 499(1-2), 106-110. 